\title{
Testicular mass in a resting cell
}

\section{S Puppala, M Taneja, D Cochlin}

Answers on $p 742$.

A 21 year old man was referred by his general practitioner for an ultrasound evaluation of bilateral testicular masses. The masses were insidious in onset, slow growing, and palpable. There were no other local signs. The patient was also under the care of an endocrinologist for congenital adrenal hyperplasia.

His current therapy included hormone replacement with oral steroids.

However the patient was non-compliant with regards to his medication. An ultrasound scan was performed as shown in figs 1 and 2 .

\section{QUESTIONS}

(1) What does the ultrasound scan show?

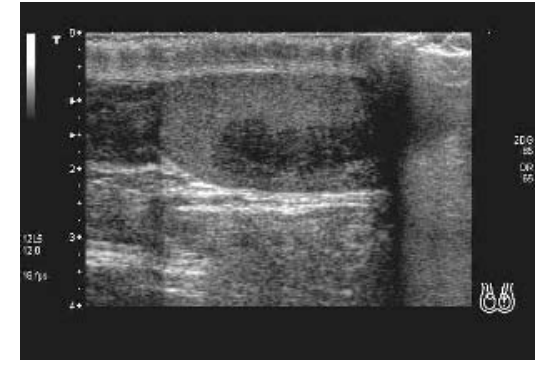

Figure 1 Left testis.

(2) Given the patient's history, what is the diagnosis?

(3) Describe the pathophysiology of these lesions?

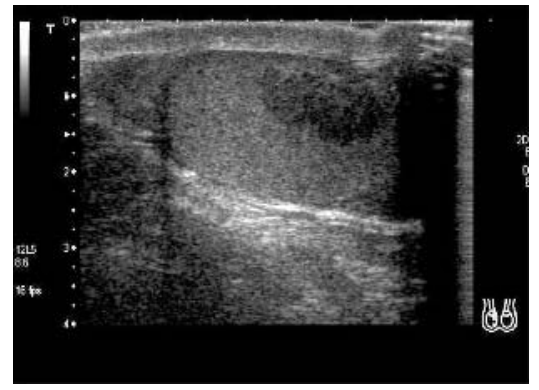

Figure 2 Right testis.

(4) What is the role of imaging in the management of these lesions?

Postgrad Med J 2004;80:740.

doi: 10.1136/pgmi.2003.013565

\section{Authors' affiliations}

S Puppala, M Taneja, D Cochlin, Department of Radiology, University Hospital of Wales, Cardiff, UK

Correspondence to: Dr Sapna Puppala, University Hospital of Wales, Cardiff CF14 4XW, UK; puppalasapna@hotmail.com

Submitted 13 August 2003 Accepted 2 October 2003

\section{Pathological fracture in a pregnant woman

\author{
P Chaturvedi, A Puri, M G Agarwal, P S Pai, K A Pathak, \\ D A Chaukar, M S Deshpande, A K Decruz
}

\section{Answers on $p 743$.}

\section{QUESTIONS}

(1) What is the differential diagnosis based on the history and the MRI (giant cell tumour, brown tumour, chondrosarcoma, secondaries in the bone)?

(2) What other relevant blood investigation should be ordered in such patients (calcium, parathyroid hormone, alkaline phosphatase, acid phosphatase)?

Postgrad Med J 2004;80:740. doi: $10.1136 /$ pgmi.2003.017103

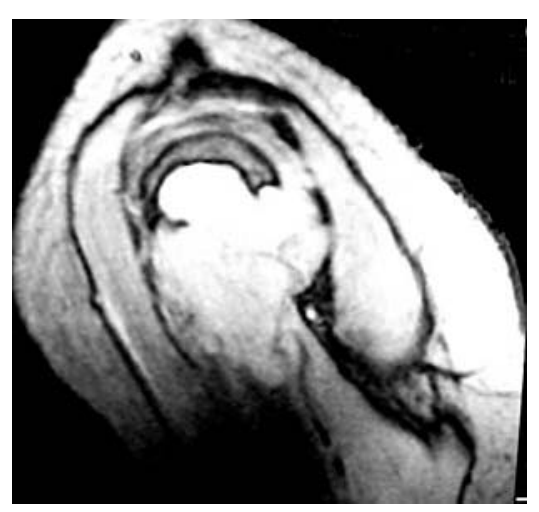

Figure 1 MRI showing a lytic lesion with pathological fracture and soft tissue extension in the upper end of the humerus.

\section{Authors' affiliations}

P Chaturvedi, A Puri, M G Agarwal, P S Pai, K A Pathak, D A Chaukar, M S Deshpande, A K Decruz, Department of Surgery, Tata Memorial Hospital, Mumbai, India

Correspondence to: Dr Pankaj Chaturvedi, Assistant Professor, Tata Memorial Hospital, EB Road, Parel, Mumbai 400 012; pankajch37@ yahoo.com

Submitted 15 November 2003 Accepted 15 January 2004 